\title{
EL VETO MEXICANO HACIA TEXAS, EL INCIDENTE DE EL PASO Y SU INFLUENCIA EN EL PROCESO NEGOCIADOR del Programa Bracero $(\text { I } 947-\text { I 949) })^{\mathrm{I}}$
}

ENRIQUE GARCÍA SEARCY

\section{INTRODUCCIÓN}

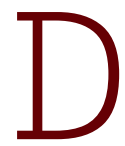
urante la década de 1940, la república mexicana es insertada dentro del bloque americano en lucha contra el fascismo y posteriormente se ve obligado a declarar la guerra a las llamadas "Potencias del eje", iniciando así un periodo de crecimiento económico y expansión industrial a la sombra de los Estados Unidos. Fue durante este marco de cooperación internacional en tiempos de guerra cuando nace la necesidad de implementar un programa de importación de mano de obra temporal en los Es-

1 El presente artículo es producto de exhaustiva investigación archivo tanto en México como en los Estados Unidos, en el que destacan el archivo de la Embajada de México en Washington, ubicado en el Acervo Histórico de la Secretaría de Relaciones Exteriores (SRE) en la Ciudad de México; archivos generados por la Texas Good Neighbor Commission depositados en The Lorenzo Zavala Texas State Archives y diversos fondos históricos dentro de las colecciones especiales de The Natee Lee Benson Latin American Collection en UT Austin; la cual forma parte de la tesis doctoral del autor titulada "Entre la racializacion y el olvido: la diplimacia mexicana, la agroindustria texana y la defensa de los trabajadores agrícolas mexicanos durante el Programa Bracero".

2 El autor es licenciado en Historia por la Universidad Autónoma de Baja California, maestro en Demografía por El Colegio de la Frontera Norte y doctor del programa de Doctorado en Ciencias Sociales con especialidad en Historia Regional impartido por la Universidad Autónoma de Ciudad Juárez. 
tados Unidos conocido popularmente como Programa Bracero (en adelante $\mathrm{PB}$ ), el cual contó con un particular interés por parte de productores agrícolas texanos y californianos; siendo en agosto de 1942 cuando se llega a un acuerdo para la importación de mano de obra mexicana a Estados Unidos en el sector agrícola y unos meses después fue ampliado al sector ferrocarrilero. ${ }^{3}$

El PB transformó el discurso de las relaciones diplomáticas entre ambas naciones supliéndolo por un mensaje de cooperación y apoyo mutuo entre gobiernos; no obstante, la realidad económicolaboral siguió siendo la misma. Las pésimas condiciones laborales para los trabajadores agrícolas mexicanos permanecieron constantes y el gobierno de México poco a poco fue cediendo a las presiones de su contraparte estadounidense, legitimando la explotación laboral en aras de un acuerdo internacional. Los 22 años del periodo de vigencia del PB constituyen una etapa clave para entender las relaciones diplomáticas entre México y los Estados Unidos; por lo cual no debe ser visto como proceso aislado sino como un continuo histórico de las tensas relaciones diplomáticas entre ambos países caracterizadas por la asimetría política y económica.

El estado de Texas ha jugado un papel clave en la historia de las relaciones entre México y los Estados Unidos, no solo por la cantidad de mexicanos que radican en dicha entidad, sino por los antecedentes de maltratos y vejaciones sufridas a manos de los anglo-texanos. ${ }^{4}$ El énfasis que esta investigación hace sobre el in-

3 Para mayor información sobre el programa de importación de mano de obra ferrocarrilero durante la Segunda Guerra Mundial se recomienda consultar: Erasmo Gamboa (2016) Bracero Railroaders: The Forgotten World War II Story of Mexican Workers in the U.S. West, University of Washington Press; Barbara Driscoll (1999) The Tracks North: The Railroad Bracero Program of World War II, University of Texas Press.

4 Existe una amplia tradición historiográfica por parte de varias universidades de centros de investigación en los Estados Unidos sobre la historia de la comunidad mexicana radicada en Texas, destacando los siguientes textos: Arnoldo De León (1983), They Called Them Greasers: Anglo Attitudes Toward Mexicans in Texas, 1821-1900, University of Texas Press, 153 pp.; Neil Foley (1999), The White Scourge: Mexicans, Blacks, and Poor Whites in Texas Cotton Culture, University of California Press, 320 pp.; Emilio Zamora (2003), The World of the Mexican Worker in Texas, Texas A\&M University Press, 285 pp.; Cynthia E. Orozco (2009), No Mexicans, Women, or Dogs Allowed: The Rise of the Mexican American Civil Rights Movement, University of Texas Press, 316 pp.; Martha Menchaca (2011), Naturalizing Mexican Immigrants: A Texas History, University of Texas Press, 372 pp.; Matthew Gritter (2012), Mexican In- 
cidente de El Paso y la Texas Good Neighbor Commission, buscan pasar más allá de lo anecdótico pues son un reflejo de las actitudes de rechazo hacia los mexicanos prevalentes en los sectores más conservadores de la sociedad texana. Estas actitudes discriminatorias se han presentado históricamente desde la conformación de la frontera tras la firma del tratado de Guadalupe-Hidalgo y consolidado con el proceso migratorio mexicano a Estados Unidos que cuenta con más de 130 años de continuidad, afectando las relaciones diplomáticas entre ambos países; ya que se encuentran implicados intereses económicos locales, vínculos sociales individuales que trascienden la línea fronteriza y habiendo influido en la conformación actual de ambos estados nacionales.

\section{ORÍGENES DEL PROGRAMA BRACERO}

La incorporación de México a la SGM provocó un incremento de las exportaciones de materias primas, la mayoría de ellas dirigidas hacia los Estados Unidos lo que originó un considerable aumento en su producción industrial, además de favorecer la reducción de las tarifas arancelarias de aquel país a muchos productos mexicanos; al mismo tiempo, aumentaron las importaciones de productos manufacturados de origen estadounidense hacia México, resultando para Estados Unidos la solución al problema de colocar los productos que por causa del conflicto armado, no pudo posicionar en Europa. Dicha situación "obligó a México a orientar la mayor parte de su comercio exterior hacia su vecino del norte, que de poco más de la mitad en 1939, pasó al 80 \% en 1945” (Rivero, 1990: 23), incentivando así la actividad comercial en los diversos puertos fronterizos del norte de México.

La cooperación económica entre México y Estados Unidos durante este periodo no fue solamente en enceres materiales, la exportación de mano de obra mexicana hacia Estados Unidos también jugó un papel preponderante en la relación binacional. Al enviar una gran cantidad de su fuerza de trabajo a combatir

clusion: The Origins of Anti-Discrimination Policy in Texas and the Southwest, Texas A\&M University, 160 pp., entre otros. 
en batalla y centrar su economía en la industria, el sector agrícola estadounidense presentó un déficit de mano de obra, mientras que en México existía una gran cantidad de población dispuesta a trabajar en el campo estadounidense. El aumento en la demanda de mano de obra en el campo estadounidense ocasionó un incremento en el flujo migratorio de campesinos mexicanos a aquel país de manera indocumentada, sobre todo en los estados fronterizos de Texas y California, donde ya existía una fuerte tradición migratoria (Zazueta, 1978).

Si bien, la migración de mexicanos hacia Estados Unidos por motivos laborales ha sido una constante desde mediados del siglo XIX, es en el marco de esta cooperación cuando se institucionaliza y legitima por parte de los dos gobiernos. Estados Unidos se interesaba en tener un control sobre la cantidad de personas que ingresaban a dicho país, y por su parte, el gobierno mexicano se encontraba interesado en la protección de sus connacionales (Grove, 1996); por lo tanto, los gobiernos de ambos países firmaron un convenio mediante el cual se permitía una entrada controlada de trabajadores mexicanos del sexo masculino, el cual fue popularmente conocido en México como Programa Bracero (PB). ${ }^{5}$

El 4 de agosto de 1942 se firmó el primer convenio de trabajadores huéspedes mexicanos en los Estados Unidos. Hasta aquel entonces no existía precedente alguno sobre un acuerdo de carácter binacional que pretendiera regular dicho flujo migratorio, ${ }^{6}$ por lo que fue anunciado con bombo y platillo por ambos gobiernos como "un gesto de buena voluntad entre naciones amigas" que solucionaba finalmente uno de los principales problemas sociales originados con el establecimiento de la línea divisoria a mediados del siglo XIX, el PB suponía poner fin del sistema de enganche

5 Originalmente el convenio comprendía dos diferentes contratos laborales, tanto para trabajadores agrícolas como para ferroviarios, sin embargo, para objetos de este trabajo solamente nos enfocaremos en los trabajadores del sector agrario.

6 Aunque autores como Fernando Alanís, en su libro El primer programa bracero y el gobierno de México (1999), narra la existencia de un programa de contratación temporal de trabajadores mexicanos en algunos estados del suroeste estadounidense durante 1917 y 1919, el cual sentó bases para el establecimiento del PB en 1942, se trató realmente de un programa emprendido de manera unilateral en los Estados Unidos sin ninguna participación en su diseño por parte de autoridades mexicanas. 
que operaba desde finales del mismo, el cual garantizaba la transportación de trabajadores agrícolas mexicanos hacia los Estados Unidos mediante el contrato de compañías particulares, sin ningún tipo de control por parte de los dos gobiernos; así como otorgarle mayores garantías a los campesinos de origen mexicano. Sin embargo, esto no fue suficiente para modificar sustancialmente las condiciones de vida de los trabajadores agrícolas en Estados Unidos.

El acuerdo estipulado consistía en una serie de garantías y obligaciones que regulaban la relación laboral entre trabajadores agrícolas mexicanos y administradores o dueños de granjas en $\mathrm{EU}$, que se encontraban mediados y vigilados por las autoridades federales de ambos países. Cabe destacar que, de acuerdo a las condiciones originales del tratado, la Farm Security Administration (FSA), del Departamento de Agricultura, contrataba directamente a los braceros, misma que los refería a un "subempleador", el cual era un propietario o administrador de una o más fincas agrícolas. Lo cual significaba que el gobierno de los Estados Unidos, a través de la FSA, tenía la obligación de encargarse de la transportación y de garantizar condiciones de "vida digna" a los trabajadores mexicanos.

Los contratos entre el empleador y el trabajador se redactarían en español y bajo la supervisión del gobierno mexicano, el cual determinaría en cada caso el número de trabajadores que puedan salir "sin quebranto de la economía nacional"; por su parte, las autoridades sanitarias mexicanas cuidarían en los lugares de origen que se reunieran las condiciones físicas necesarias, mientras que los cónsules mexicanos extremarían "las medidas de protección de los intereses de los trabajadores mexicanos en todas las cuestiones que les afectaran dentro de las jurisdicciones correspondientes". Entre las garantías ofrecidas a los jornaleros mexicanos estaban el ser empleados exclusivamente en el trabajo para el que hubiesen sido contratados, no pudiendo ser utilizados en servicio militar; y evitando que sufrieran actos discriminatorios de alguna naturaleza; no ser empleados para desplazar a otros trabajadores, ni para abatir salarios previamente establecidos. 


\section{EL VETO TEXANO}

La larga tradición migratoria mexicana hacia dicha entidad y el antecedente de conflictos internacionales graves, como lo fue la guerra entre México y Estados Unidos, propiciaron un ambiente hostil hacia los mexicanos, por lo que se podría considerar a Texas un "caso especial"; las prácticas de exclusión y segregación racial eran comunes en aquel país, principalmente en los estados del sur, donde se concentraba la mayor parte de los campos agrícolas a los que fueron enviados. De acuerdo a autores como Gilbert González (1999), la política del gobierno mexicano de vetar a Texas bajo la justificación de antecedentes de malos tratos hacia sus connacionales, no fue la más acertada, puesto que no garantizaba mejora alguna sobre las condiciones de vida a los trabajadores mexicanos. En estados como Kansas, Arkansas, Oklahoma, Tennessee e incluso California, que recibieron un gran número de braceros, las políticas de segregación racial conocidas como Jim Crow Laws, eran una realidad que distaba mucho de desaparecer.

Ante estas condiciones los gobiernos federal estadounidense y el texano intentaron realizar ciertas medidas que convencieran a las autoridades migratorias mexicana para la inclusión de Texas en el citado convenio laboral. En junio de 1943, el entonces gobernador texano, Coke Stevenson promulgó la Caucasian Race Resolution, una ley en la que proclamaba que todo ciudadano de cualquier nación latinoamericana (incluyendo México), sería considerado legalmente caucásico ante el Estado norteamericano; semanas después se decreta la creación de la Texas Good Neighbor Commission, que se encargaría de entablar relaciones cordiales con México en temas como límites geográficos y migración internacional. A pesar de que las medidas mencionadas en el párrafo anterior consistieron en grandes avances para la comunidad mexicana y mexicoamericana residente en Texas, el gobierno mexicano consideró insuficientes las medidas tomadas desde Austin y mantuvo su postura, en buena parte por su falta de difusión en medios que no fueran hispanohablantes.

Uno las principales objeciones por parte de la SRE era que dicha proclamación no establecía ninguna sanción a quien no la 
acatara, por lo que no tenían ninguna validez de facto y solo se quedaba en una declaración de buenas intenciones. En respuesta a ello, el gobierno mexicano a través del Cónsul General en San Antonio, propuso como alternativa ante el Juez de Distrito Cullen Briggs, la creación de "un Comité Ejecutivo con amplias facultades para presionar a los que practiquen la segregación y en caso de que no se tuviera éxito por la vía amistosa estar en condiciones para recurrir a los tribunales por la vía del amparo", sin embargo, dicha propuesta fue rechazada por las autoridades estadounidenses.

Pese a la exclusión de Texas del PB, existía un flujo importante de campesinos mexicanos que buscaban laborar en los Estados Unidos, así como una fuerte demanda de su trabajo, por lo que muchos de los candidatos a braceros que no cumplían con alguno de los requisitos o eran rechazados, ingresaban a los Estados Unidos con el fin de ser contratados de manera indocumentada. Dicho fenómeno se pudo observar a lo largo de la frontera, sin embargo, fue en Texas donde se presentó de manera más contundente tanto por las facilidades de transportación como por la misma ausencia del programa. Estos trabajadores usualmente eran utilizados en cosechas temporales y pasando el tiempo de la cosecha regresaban a territorio mexicano, usualmente a las ciudades fronterizas en busca de ser re-contratados".

A pesar de la constante migración indocumentada, algunos granjeros texanos buscaban establecer relaciones con el Estado mexicano para que les fueran enviados trabajadores, debido a que la mano de obra indocumentada resultaba insuficiente para satisfacer la demanda de cosecha. A finales de junio de 1943, el Juez Cullen Briggs se entrevistó con el cónsul general de San Antonio, Luis L. Duplan con la finalidad de que interceda para que el gobierno mexicano autorice el envío de diez mil trabajadores para la cosecha de algodón en Corpus Christi, Texas; ${ }^{8}$ y para julio de ese mismo años el gobernador de Texas Coke Stevenson realizó

7 Archivo de la embajada de México en los Estados Unidos, AHSRE, legajo 1952, expediente 2 .

8 Archivo de la embajada de México en los Estados Unidos, AHSRE, legajo 1952, expediente 2 . 
la misma petición, la cual fue negada ambas veces por parte de las autoridades mexicanas. ${ }^{9}$ El flujo de mano de obra mexicana indocumentada se mantuvo constante, aunque se tomaron algunas medidas por parte de las autoridades migratorias para impedir que por mecanismos oficiales y extraoficiales, miles de trabajadores agrícolas siguieran ingresando de manera irregular, no solo a Texas sino a otras entidades de los EU. ${ }^{10}$

\section{EL COVENIO DE 1947: UN ACUERDO DE POSGUERRA}

La rendición de Japón en agosto de 1945 frente a tropas estadounidenses puso fin a la SGM, y con ello se daban por concluidos los convenios de trabajadores migratorios entre México y los Estados Unidos. No obstante, a causa de los compromisos comerciales de los productores estadounidenses, la incapacidad del gobierno mexicano para transportar a todos los braceros desde la frontera hasta los centros de contratación de origen, y el uso intensivo de las vías férreas estadounidenses para transportar a sus lugares de origen a las tropas que pelearon en los frentes del Atlántico y Pacífico; se optó por retrasar la culminación del mismo. La incertidumbre generada por la incapacidad de movilizar oportunamente a todos los braceros a raíz del final de la SMG generó un vacío de poder e inestabilidad en el funcionamiento del programa, por lo que resultaba evidente que se tomaran las medidas necesarias para que su culminación se realizara los más ordenadamente posible.

Entre el 27 de enero y el 4 de febrero de 1947, se realizaron una serie de encuentros en la Ciudad de México, donde representantes de ambos países discutieron la posibilidad de amparar dentro de la protección del programa, es decir "legalizar", a los trabajadores mexicanos indocumentados que se encontraban laborando en los Estados Unidos, lo cual, en teoría, le garantizaría mejores condiciones laborales a los trabajadores; posteriormente

9 Archivo de la embajada de México en los Estados Unidos, AHSRE, legajo 1451, expediente 20

10 Archivo de la embajada de México en los Estados Unidos, AHSRE, legajo 1451, expediente 22, foja 80. 
el 10 de marzo, mediante un intercambio de notas diplomático, se aprobó dicha práctica la cual sería popularmente conocida como "secado de mojados". Según a lo establecido en el acuerdo, el trabajador mexicano indocumentado debería ser transportado a territorio mexicano por cuenta del empleador estadounidense en los puertos fronterizos de Mexicali, Ciudad Juárez o Reynosa, una vez estando en territorio mexicano, el patrón debería demostrar ante autoridades migratorias mexicanas que el trabajador era de nacionalidad mexicana y que el empleador cumplía con todos los requisitos para garantizarle al trabajador unas condiciones laborales consideradas aceptables, al ser corroborados estos datos se procedía a la firma del contrato bajo supervisión de autoridades mexicanas para posteriormente devolverse a los campos agrícolas donde continuaría laborando.

En el citado acuerdo, se especificó que se trataba de una disposición de carácter temporal y excepcional, y que de ninguna manera buscaba desplazar a los centros de contratación ya establecidos en México; además que ambos gobiernos se comprometerían a reforzar la vigilancia en sus fronteras para impedir que trabajadores mexicanos siguieran ingresando a los Estados Unidos de manera indocumentada y sin ninguna protección laboral. Ese mismo día, mediante otro intercambio de notas, se otorga permiso especial, también como medida excepcional, para que agricultores del estado de Texas pudieran realizar la práctica del "secado de mojados" ya que (debido a la política del veto y su contigüidad geográfica con México) era la entidad estadounidense con mayor cantidad de indocumentados. No obstante, en octubre de ese mismo año, el gobierno mexicano decide revocar el acuerdo en Texas, ya que las discriminaciones hacia ciudadanos mexicanos seguían siendo una constante en ese estado.

Aunque se tiene poca información acerca del periodo de poco más de siete meses (del 10 de marzo al 15 de octubre de 1947), en el que se permitió la legalización de trabajadores indocumentados en Texas, constituye un episodio clave para la historia laboral de los mexicanos radicados en aquella entidad, por lo que se considera pertinente un estudio más a fondo sobre este periodo, 
el cual ha sido poco estudiado por académicos de ambos lados de la frontera. Este acuerdo fue importante, ya que además de formar un precedente para las posteriores negociaciones, se trató de la primera vez que en una comunicación oficial firmada por autoridades de ambos países, se reconoce como "un problema" la migración indocumentada de mexicanos hacia Texas.

Días después, en un intercambio de notas realizado entre los días 25 de marzo y 2 de abril de 1947, se realizaron algunas reformas al convenio de importación de mano de obra agrícola aún vigente. ${ }^{11}$ Estando cercana la fecha fijada para la terminación del convenio, una comitiva formada por altos mandos diplomáticos y migratorios de ambos países, se reunieron en una serie de conferencias realizadas en El Paso, entre el 20 de noviembre y el 2 de diciembre de 1947, y en la Ciudad de México, del 9 al 11 de febrero de 1948, donde discutieron los pormenores para la promulgación de un nuevo convenio. Como resultado de esas sesiones de trabajo, el 21 de febrero de 1948, se firmó un nuevo acuerdo laboral, con la aprobación de dicho acuerdo se sustituía a los anteriormente establecidos, por lo que los convenios donde se aprobaba la política del secado de mojado, y otros puntos acordados quedaban sin validez.

Las nuevas condiciones dejaban en una posición de mayor vulnerabilidad al trabajador mexicano. Sin lugar a dudas, el cambio más notable fue el tipo de relación contractual, pasando a ser de una relación entre dos entidades de gobierno, a una de particulares. La Farm Security Administration, ${ }^{12}$ quien fue la agencia federal encargada de realizar las contrataciones de trabajadores mexicanos en los Estados Unidos, ya no sería más la entidad empleadora, pasando su atribución al dueño o administrador de la finca y dejando, por tanto, de ser responsabilidad del gobierno estadounidense el cubrir con los gastos de transporte y alimentación del trabajador mexicano. Los patrones que quisieran contratar trabajadores mexicanos bajo esta modalidad deberían estar inscritos

11 Siendo la versión revisada del acuerdo que se aprobó el 26 de abril de 1943, en el que ya se incluía también el programa ferrocarrilero.

12 La Farm Security Administration fue completamente restructurada en agosto de 1946, siendo renombrada como Farmers Home Asministration (FHA). 
en el Immigration and Naturalization Service (INS) y depositar una fianza o garantía colateral para garantizar el retorno del trabajador.

Aunque el gobierno mexicano desde los centros de contratación tenían la obligación de realizar rigurosos exámenes médicos para garantizar la buena condición física de los trabajadores migrantes, a partir de 1948 se estableció que el Public Health Service (PHS) podría realizar una segunda revisión médica en caso de considerarla necesaria. Los aspirantes a bracero que no cumplieran con los requisitos del PHS serían regresados a sus centros de contratación de origen y el costo de transportación debería ser asumido por las autoridades estadounidenses.

La preocupación por parte del gobierno mexicano para restringir el número de trabajadores migrantes que se dirigían a los Estados Unidos se mantuvo constante, por lo que al menos en el papel, la autorización a contratar trabajadores mexicanos debería ser negada a aquellos patrones que utilizasen trabajadores internados "ilegalmente". Por otro lado, con motivo de no despoblar la franja fronteriza, los residentes de esas poblaciones, poseedores de tarjetas de identidad $5 \mathrm{C}^{13}{ }^{13}$ serán excluidos de contrataciones.

Este acuerdo igual que los anteriores, contenía una cláusula en la que se especificaba la prohibición de contrato a trabajadores mexicanos en zonas de fuerte tradición discriminatoria contra ciudadanos de esa nacionalidad, sin especificar cuáles eran estas; sin embargo, el mismo día de la firma del convenio, el gobierno mexicano mandó un comunicado a sus diferentes consulados en que explícitamente se asentaba:

No se autorizarán recontrataciones en los estados de Texas, Mississippi, Arkansas, partes occidentales de Missouri, Kansas, los llamados Estados del Sur y, en general, en los Condados y fincas donde se hayan registrado frecuentes casos de discriminación contra mexicanos". ${ }^{14}$

13 Este documento solamente era otorgado a residentes de zonas fronterizas y servían como tarjeta de identificación durante el cruce fronterizo.

14 Memorándum de la SRE a consulados mexicanos, 21 de febrero de 1948, en Archivo de la embajada de México en los Estados Unidos, en Archivo de la embajada de México en los Estados Unidos, AHSRE, legajo 1452, exp 1. 


\section{EL PLAN STILLEYY LA LISTA NEGRA}

Entre los meses de enero y febrero de 1948, en el marco de la conferencia binacional para la renovación del convenio laboral agrícola llevada a cabo en El Paso; se realizó un encuentro entre Thomas S. Sutherland, en calidad de secretario ejecutivo de la TGNC; el cónsul mexicano en San Antonio, Miguel G. Calderón y el representante de la Texas Cotton Ginner's Association, Jay C. Stilley, donde se discutió la posibilidad de realizar una campaña en contra de la discriminación hacia ciudadanos mexicanos auspiciada por las compañías algodoneras texanas, con el objetivo explícito de convencer al gobierno mexicano de "levantar el veto contra Texas" permitiendo para junio de ese mismo año, la entrada de braceros mexicanos para levantar la cosecha de algodón en Texas.

El plan de acción propuesto por la Texas Cotton Ginners Association, y el cual fue conocido como Plan Stilley, consistía en: a) emprender un canal comunicación permanente entre la asociación de algodoneros, los consulados mexicanos en Texas, y la TGNC, otorgándoles listas detalladas con información de contacto de sus asociados; b) otorgarle al cónsul general de San Antonio reportes sobre escuelas y centros industriales o agrícolas donde se practicara la discriminación contra mexicanos; c) realizar una serie de reuniones entre empresarios, agricultores, oficiales de paz y la comunidad en general, para promover el alto a las políticas discriminatorias en contra de mexicanos, mandando una copia de lo acordado en cada reunión al Cónsul mexicano en San Antonio; d) en esas reuniones, los granjeros texanos discutirían las condiciones de vivienda y salarios que deberían tener los trabajadores mexicanos; y e) establecer comités locales responsables de investigar los casos de discriminación hacia mexicanos, el cual trabajaría en conjunto con la TGNC y los consulados mexicanos. ${ }^{15}$

15 Resumen de "El Plan Stilley" en el reporte mensual de la Texas Cotton Ginners Association, abril 21 de 1948, en Beauford H. Jester records, 1946-1949, The Lorenzo Zavala Texas State Archives Caja 4-14-69, Exp. 35 
A finales de marzo, fueron envidadas copias del plan a las oficinas de la Texas Good Neighbor Commission y al consulado mexicano en San Antonio, donde además se les comunicaba que esperaban contar con su plena colaboración para que esta idea se llevara a cabo conforme a lo planeado. El día 29 de marzo de 1948 Thomas Sutherland envió un telegrama al señor Stilley en el que le comentaba que se encontraba con toda la disposición para colaborar con su plan y que veía en él una excelente estrategia para convencer al gobierno mexicano de poner fin a su política de veto en dicha entidad; ${ }^{16}$ no obstante al día siguiente, 30 de marzo de 1948, en tono menos amistoso, el cónsul general de San Antonio responde vía telegrama la carta enviada por la Texas Cotton Ginners, informándoles que:

Me complace informar que considero que el Plan de Stilley será constructivo y útil en la eliminación de la discriminación de los mexicanos en Texas. [Aprovecho este medio para] dejar en claro [que] Gobierno de México no tiene ninguna lista negra sino que simplemente ha adoptado medidas excepcionales para [la] protección [de] sus nacionales mexicanos en vista de las circunstancias excepcionales que prevalecen este estado. [Además, deseo] sugerir que [se] experimente [el] plan de Stilley con ciudadanos americanos de origen mexicano con el fin de apreciar sus buenos resultados. ${ }^{17}$

Ante la respuesta evasiva del cónsul Calderón, Jay C. Stilley envía una carta con fecha del 9 de abril dirigida al Consulado mexicano en San Antonio, donde solicitaba un posicionamiento definitivo respecto al citado plan, ya que requería saber si contarían o no con trabajadores mexicanos para levantar la cosecha de algodón de 1948:

Estamos ansiosos y dispuestos a trabajar con usted en este o cualquier otro plan que se presentó que reúna los requisitos de su

16 Copia de telegrama de enviado el 29 de marzo por T. S. Sutherland a J. C. Stilley en boletín de la Texas Cotton Ginners Association, abril 21 de 1948.

17 Telegrama enviado el 30 de marzo por M. G. Calderón a J. C. Stilley en reporte mensual de la Texas Cotton Ginners Association, abril 21 de 1948. 
gobierno. [Por lo] que pedimos hacer es que [se realice] alguna decisión definitiva de forma que nuestros agricultores de Texas sean informados en cuanto a si puede contar con los ciudadanos mexicanos para la cosecha de 1948 de algodón. ${ }^{18}$

Entre los meses de marzo y junio de 1948, la Texas Cotton Ginners se encargó de coordinar a algodoneros locales para que emprendieran el citado plan en cada uno los condados texanos con fuerte producción agrícola. En informes enviados por los algodoneros locales a la asociación estatal presidida por J. C. Stilley, se obtuvieron algunos avances relacionados con la campaña para eliminar la discriminación a mexicanos en lugares públicos y distritos escolares. ${ }^{19}$

El consulado mexicano no volvió a enviar más comunicados a la Texas Cotton Ginners Association; sin embargo, a pesar del silencio del gobierno mexicano ante los algodoneros texanos, el 10 de mayo de 1948, el gobierno mexicano le otorgó por primera vez un permiso para importación de trabajadores mexicanos, a la asociación de algodoneros del condado de Jefferson en Arkansas. Al día siguiente, los agricultores Earl T. Wells y James P. Baker expidieron un comunicado, a nombre de la asociación de agricultores del condado de Phillips Arkansas y dirigido al cónsul Calderón, donde solicitaban que se les otorgara un permiso para la importación de 360 trabajadores agrícolas mexicanos, comprometiéndose a otorgarles un salario justo, viviendas decorosas, atención médica, seguro por accidente de trabajo, entre otras garantías; ${ }^{20}$ solicitud que fue negada por el gobierno mexicano.

Días después, en un boletín de prensa de la Secretaría de Relaciones Exteriores, con fecha del 22 de mayo, ${ }^{21}$ el gobierno mexicano informó que se encontraba realizando investigaciones

18 Copia de carta enviada por J.C. Stilley al consulado mexicano en San Antonio, 9 de abril de 1948, en ídem (subrayado en texto original)

19 Boletín de The Texas Cotton Ginners Association, Abril 12 de 1948, en ídem.

20 Comunicado de E.T. Wells y J.P. Baker al cónsul mexicano en San Antonio M.G. Calderón, 11 de mayo de 1948, en Archivo de la embajada de México en los Estados Unidos, AHSRE, Legajo 1452, Exp 7

21 Boletín de Prensa de la SRE, 22 de mayo de1948, en ídem. 
en los estados de Arkansas y Misisipi para evaluar la posibilidad de mandar jornaleros mexicanos a dichas entidades en un futuro cercano, si es que se demostraba una disminución notable de casos de discriminación hacia ciudadanos mexicanos.

No fue sino hasta el 25 de mayo, cuando el cónsul Calderón envía un comunicado a Stilley, donde una vez más le informaba que "no existía ninguna lista negra" por parte del gobierno mexicano y que este se encontraba dispuesto a mandar trabajadores a dicha entidad en cuanto se demostrara "un mejoramiento sustancial de las condiciones de trato a ciudadanos mexicanos". De igual manera, aunque reconocen algunos esfuerzos en ciertas regiones algodoneras del estado con el objetivo para eliminar la discriminación hacia mexicanos, estos fueron considerados "insuficientes", por lo que recomendaron una aplicación más rigurosa del plan Stilley en otras regiones de Texas, así como endurecer las medidas para la prohibición de trabajadores indocumentados por parte de granjeros texanos. ${ }^{22}$

Ante el posicionamiento por parte del cónsul Calderón, Stilley responde lo siguiente:

Le agradezco mucho su atenta carta de 25 de mayo, y aunque deduzco por ella que la respuesta del Gobierno mexicano a nuestra petición de trabajadores quiere decir que 'no', deseo asegurarle a usted que estimo en todo lo que vale la atención personal que se sirvió dispensarle a este asunto. ${ }^{23}$

Durante el mes de junio, la Texas Cotton Ginners Association realizó un último intento para convencer al gobierno mexicano para que les fueran enviados braceros a los campos algodoneros texanos. En uno de los boletines de la asociación, Stilley anunció que realizaría un viaje a la ciudad de México donde presentaría una versión más ambiciosa del Plan Stilley ante la Secretaría de Relaciones Exteriores, a su vez, informó que buscaría estrechar

22 Carta del cónsul Calderón a J.C. Stilley, 24 de abril de 1948, en ídem.

23 Traducción al español de comunicado de J.C. Stilley al cónsul general de México en San Antonio M.G. Calderón, 29 de mayo de 1948 en Archivo de la embajada de México en los Estados Unidos, AHSRE, Legajo 1452 , Exp 7 
sus relaciones con LULAC (League of United Latin American Citizens), una asociación de mexicoamericanos comerciantes y profesionistas de clase media y alta que mantuvo una postura especialmente crítica con respecto al $\mathrm{PB}^{24}$

Por otro lado en esa misma semana, el secretario del gobierno texano George C. Marshall, realizó una petición a la embajada mexicana en Washington para que se enviaran 10000 braceros mexicanos para laborar en los campos algodoneros de Texas. ${ }^{25}$ Tanto las peticiones del gobierno texano como la de los productores algodoneros fueron negadas, por lo que la cosecha tuvo que ser recolectada mediante la utilización del circuito interno de migrantes agrícolas estadounidenses y el empleo de trabajadores indocumentados.

A mediados del mes de agosto, en plena temporada de recolección de algodón, la Texas Cotton Ginners Association envía a la TGNC un informe detallado sobre el estatus de la cosecha de Texas, condado por condado; según lo reportado, para el 13 de agosto, la producción algodonera del centro y sur de Texas habían alcanzado su pico de la temporada y en las zonas norte y oeste se preparaban para una cosecha récord. ${ }^{26} \mathrm{~A}$ pesar de la ausencia del PB en la entidad, los trabajadores migratorios internos e indocumentados fueron suficientes no solo para garantizar la cosecha, sino que superaron el estimado anual de producción.

\section{POR UN CENTRO DE CONTRATACIÓN EN CHIHUAHUA}

El 5 de agosto de 1948, en una reunión de trabajo entre representantes del servicio de colocaciones de los Estados Unidos y la Comisión mexicana encargada de los asuntos de trabajadores migrantes se realizó una reforma al convenio laborar en preparacio-

24 Boletin de la Texas Cotton Ginners Association, 11 de Junio de 1948 en en Beauford H. Jester records, 1946-1949, The Lorenzo Zavala Texas State Archives Caja 4-14-69 Exp. 35

25 Carta de B. H. Jester a G. C. Marshall, 16 de Junio de 1948, en ídem.

26 Boletín intemo de la Texas Cotton Ginners Association, 13 de agosto de 1948, en Archivo de la embajada de México en los Estados Unidos, AHSRE, legajo 1452, Exp. 7. 
nes para la temporada de cosecha otoñal. ${ }^{27}$ Entre otras determinaciones se resolvió permitir el ingreso de braceros mexicanos a los condados de Phillips, Saint Francis, Cross, Crittenden, Poinsett, Chicot, Craighead, Ashley, Jefferson y Mississippi, en Arkansas; Dunklin en Missouri y Jefferson y Jackson en Mississippi, todos ellos ubicados en las inmediaciones del río Mississippi; este punto causó una gran molestia entre los agricultores texanos, en especial a los algodoneros, quienes recientemente habían emprendido una campaña antidiscriminatoria con el objetivo de contar con la mano de obra mexicana para la temporada de cosecha de algodón en el verano de 1948.

Otro de los temas a abordar fue la localización de centros de contratación; el gobierno mexicano mantenía la postura de ubicarlos lo más lejos posible de la frontera norte, donde se encontraban un gran número de trabajadores agrícolas sin empleo; mientras que el gobierno estadounidense presionaba para que se establecieran más al norte, con la finalidad de reducir costos de transportación. Finalmente a raíz de las negociaciones se establecieron nuevos centros de contrataciones en Monterrey, N. L.; Culiacán, Sin.; Chihuahua, Chih. y Mexicali, B. C.; siendo estos dos últimos los que más generaron controversia: Mexicali, por ser una ciudad fronteriza, y Chihuahua, por estar cercana a una de las zonas de producción agrícola más importantes del país.

El establecimiento de un centro de contratación de braceros en Chihuahua causó polémica entre los agricultores locales (principalmente algodoneros), pues esto significaría una fuga considerable de mano de obra hacia los Estados Unidos y pondría en peligro sus cosechas. Accediendo a este tipo presiones locales, el gobierno mexicano pospuso la instalación de ese centro de contratación hasta que terminara la temporada de cosecha en México, lo cual causó preocupación y molestia, especialmente entre los agricultores Arizona y Nuevo México, quienes tendrían que contratar trabajadores provenientes de centros más lejanos.

27 Síntesis de los puntos tratados en la junta celebrada entre representantes del servicio de colocaciones de los Estados Unidos y la comisión encargada de asuntos de trabajadores emigrantes, 5 de agosto de 1948, Archivo de la embajada de México en los Estados Unidos, AHSRE, Legajo 1452, Exp. 8. 
El 3 de septiembre de 1948, Paul J. Reveley (jefe de Divission of Mexican Affairs) envió una carta a Rafael De la Colina (Encargado de negocios ad interim) donde le comentaba que A. W. Motley (Subdirector de la US Employment Service) le informó a Robert E. Wilson (oficial de política económica de la DMA) sobre la preocupación por el retraso del gobierno mexicano en establecer el centro de contratación de braceros en la ciudad de Chihuahua, y se advertía de la posibilidad de "admitir a trabajadores agrícolas mexicanos que presenten solicitudes individuales, así como legalizar a las decenas de miles de trabajadores indocumentados que continuamente entran por el estado de Texas" ${ }^{28}$ poniendo así en riesgo la continuación del convenio.

Ante esta amenaza velada por autoridades estadounidenses, en una carta con fecha del 20 de septiembre de $1948,{ }^{29}$ De la Colina le comunica a Paul J. Revelay que dicho convenio "se inspiró en un espíritu de cooperación mutua" que garantizara "la protección de los intereses de ambas naciones", y al ser considerada prioridad nacional, la cosecha de algodón en Chihuahua, las autoridades mexicanas "se ha[bían] visto precisadas a aplazar la apertura de dicho centro hasta que las cosechas se terminen", [...] "sin que esto signifi[cara] un incumplimiento del contrato". En cambio, consideró "contraria al espíritu cordial que anima al convenio, la opinión expresada por A. W. Motley” de no cumplir a cabalidad lo establecido en el convenio.

Días después, el 24 de septiembre, se reunieron en la ciudad de Washington D. C., el Secretario de Relaciones Exteriores Alfonso Guerra, Rafael De la Colina, John Flahburn, Robert E. Wilson, A. W. Motley, entre otras autoridades, en la cual se fijaron las posturas oficiales de ambos gobiernos en relación a esta crisis diplomática.

Por parte del mexicano:

a) La Secretaría de Relaciones Exteriores (SRE) exigía a las autori-

28 Ídem, Carta de Paul J. Reveley a Rafael De la Colina, 3 de septiembre de 1948.

29 Ídem, Correspondencia de Rafael De la Colina a Paul J. Reveley, 20 de septiembre de 1948. 
El veto meXicano hacia TeXas, el incidente de El Paso y su influencia...

dades estadounidenses aumentar la vigilancia en fronteras para reducir la entrada clandestina de trabajadores mexicanos;

b) se opuso al establecimiento de centros de contratación en ciudades cercanas a la frontera, siendo el caso de Mexicali una excepción;

c) consideró que las autoridades estadounidenses deberían elaborar con anticipación sus programas de contratación y determinar, en conjunto con las autoridades mexicanas, cuántos braceros se requieren en cada centro de contratación, y

d) se debía realizar una selección más cuidadosa de los trabajadores, para evitar que se contraten a individuos que carezcan de experiencia agrícola.

Mientras que por parte del estadounidense se fijaron las siguientes posturas:

a) El Departamento de Migración carecía de una guardia fronteriza suficientemente numerosa para impedir el paso clandestino de trabajadores mexicanos;

b) insistió en abrir un centro de contratación en Chihuahua, y

c) reconocieron la importancia de elaborar con mayor cuidado y anticipación sus programas de contratación, así como colaborar estrechamente con las autoridades mexicanas.

Entre los días 6 al 8 de octubre de 1948, el gobernador de Texas, Beauford H. Jester, realizó una gira por el estado de Chihuahua donde se reunió trabajo a puerta cerrada con el gobernador Fernando Foglio Miramontes, en la que ambos mandatarios discutieron temas de interés de ambas entidades; de igual manera, se reunió con los cónsules estadounidenses en las ciudades de Chihuahua y Juárez, y finalmente mantuvo un reunión de trabajo en la ciudad fronteriza de El Paso con el alcalde del condado Dan R. Ponder; trató asuntos relativos a las relaciones fronterizas con México. ${ }^{30}$

30 Informe de notas periodísticas publicadas por la prensa chihuahuense relativas a la visita del gobernador B. H. Jester, Beauford H. Jester records, 1946-1949, The Lorenzo

Chinuahua Hoy, año i 5 , Núm. Is (enero-diciembre, 2017) 


\section{EL INCIDENTE EN EL PASO}

A finales de septiembre de 1948, el gobernador de Nuevo México realizó una petición directa a su homologo chihuahuense, para que intercediera ante el gobierno federal con el objetivo de mandar 2000 braceros para laborar en la cosecha de algodón y betabel en dicha entidad. La propuesta fue aceptada por el gobierno federal y dado a que se trataba de una medida de emergencia se estudiaría la posibilidad de establecer algún centro de contratación provisional en el estado de Chihuahua. La noticia se publicó en gran parte de los diarios nacionales y replicada por estaciones de radio, lo cual ocasionó un rápido arribo de aspirantes a braceros a la localidad fronteriza de Ciudad Juárez. Sin embargo, aún existían puntos pendientes en la negociación, lo que ocasionó algunos retrasos; entre los aspectos a acordar, se encontraba un posible aumento de la cuota de trabajadores solicitada así como el establecimiento de salarios especiales dado a la condición de "emergencia".

Ya entrado el mes de octubre, seguían aspirantes a braceros atraídos por la expectativa que generaban las negociaciones; no obstante estas se encontraban trabadas. Al tanto de la situación, el gobierno mexicano mandó a Ciudad Juárez a Francisco Reyes Cortés, jefe de la oficina intersecretarial para la contratación de braceros, quien llegó a la ciudad fronteriza el 10 de octubre con la instrucción de establecer una oficina temporal de contratación en un edificio a un lado del hipódromo de la ciudad. Ese mismo día, empezaron a arribar a las inmediaciones del hipódromo "un gran número" aspirantes a braceros con la esperanza de ser contratados. El volumen de los potenciales braceros era tan numeroso que el 11 de octubre, las autoridades migratorias se vieron en la necesidad de pedir auxilio a personal de la guarnición militar en Ciudad Juárez para garantizar que la contratación se realizara en orden.

El cónsul general de El Paso estimaba que para el 12 de octubre, ya había más de 6 mil aspirantes a braceros en espera de ser

Zavala Texas State Archives, Caja 4-14-69, Exp. 34. 
contratados en los alrededores del hipódromo; sin embargo, algunos detalles pendientes en las negociaciones sobre las condiciones del contrato laboral, obligaron a las autoridades mexicanas a retrasar el proceso de contratación. El gobierno mexicano insistía en establecer una cuota salarial especial de 3 a 5 dólares por cada 100 libras de algodón recolectados para los trabajadores contratados bajo esta modalidad, pero los agricultores estadounidenses se negaban a ello argumentando que les generaría pérdidas.

Para el día 13 de octubre, aparentemente incitados por enganchadores, algunos grupos de los trabajadores agrícolas decidieron cruzar por su cuenta el río Bravo, los cuales de acuerdo a las declaraciones del cónsul Michel, fueron retornados a territorio mexicano por la patrulla fronteriza. ${ }^{31}$ No obstante al día siguiente, en una medida desesperada y accediendo a la presión de los productores locales, las autoridades migratorias estadounidenses, en conjunto con la patrulla fronteriza deciden abrir temporalmente la frontera con la finalidad de contratar fuera del programa la mayor cantidad posible de trabajadores para que se hicieran cargo de la cosecha.

De acuerdo a un informe confidencial elaborado firmado por el Cónsul General de El Paso, Cnel. Raúl Michel, las autoridades migratorias estadounidenses operaron de la siguiente manera: "Se adoptó un completo disimulo por parte de las autoridades de inmigración norteamericanas que permitió a nuestros trabajadores cruzaran el río con toda libertad. Una vez en el lado americano eran detenidos por el servicio de Patrulla [Fronteriza] de los Estados Unidos y los entregaban a la agencia de empleo del Estado de Texas y a la U. S. Employment Service quienes, a su vez, los ponían a disposición de los agricultores, dándoles el número que necesitaban, sin expedirles ninguna documentación migratoria, ni siquiera contrato verbal, pues se concretaban a subirlos a los camiones que ya tenían antemano listos, para llevarlos a las granjas". ${ }^{32}$

31 Informe sobre paso ilegal y contratación de trabajadores mexicanos, cónsul R. Michel, 15 de octubre de 1948, en Archivo de la embajada de México en los Estados Unidos, AHSRE, legajo 1453, Exp. 1.

32 Informe concentrado en los sucesos presentados en la frontera relacionado con nues-

Chinuahua Hoy, aÑo I 5 , Núm. I 5 (ENERo-Diciembre, 2017) 
Según información oficial del gobierno mexicano se estima que solamente durante el primer día de esta operación entraron de manera indocumentada 2200 trabajadores, pero algunos diarios nacionales como Excélsior afirmaba en su encabezado del 15 de octubre que fueron más de 4000 migrantes indocumentados.

La reacción del gobierno mexicano no se hizo esperar: al día siguiente por órdenes directas del presidente Miguel Alemán, se suspendió temporalmente cualquier envío de trabajadores mexicanos a los Estados Unidos y mandó a personal del ejército mexicano a sellar la frontera en los alrededores de Ciudad Juárez con la finalidad de impedir el flujo de trabajadores migrantes; no obstante la operación fue un fracaso, solamente fueron capturados 400 hombres mientras que se calcula que más de 3000 lograron ingresar a Estados Unidos por diversos puntos de cruce. Al día siguiente se recibe la orden de cerrar todos los centros de contratación dando por concluido el PB por parte del gobierno mexicano.

Aunque el 18 de octubre el gobierno de los Estados Unidos, envió un mensaje a la embajada mexicana en Washington informándole que la medida de excepción ya había concluido, y que estaban dispuestos a establecer negociaciones para restablecer el convenio de trabajadores agrícolas; ${ }^{33}$ ese mismo día Rafael de la Colina, encargado de Negocios ad interim de México, mandó una carta de extrañamiento al Secretario de Estado Robert A. Lovett, sobre los acontecimientos ocurridos en la ciudad de El Paso, donde además de pedir explicaciones de lo sucedido, critica la actitud tomada por el INS mediante los siguientes puntos:

La actitud asumida por las autoridades de Inmigración de los Estados Unidos hubiera podido explicarse, acaso, como un resultado del elemento sorpresa, a no ser por cuatro circunstancias muy significativas:

a) Existían ya trenes y camiones dispuestos para el transporte de los braceros,

33 Boletín de prensa de la SRE, 18 de octubre de 1948, en Archivo de la embajada de México en los Estados Unidos, AHSRE, legajo 1452, Exp. 8. 
b) no se impidió que los trabajadores fueren distribuídos [sic] por esos en camiones y trenes,

c) los camiones y trenes no fueron detenidos en ningún punto de su trayecto, y

d) de los dos mil inmigrados ilícitos solo un grupo fué [sic] reintegrado a territorio de mi país". ${ }^{34}$

Como respuesta a ello, la Secretaría de Estados Unidos expide un memorándum a la embajada mexicana recordándole que de acuerdo a los estatutos del convenio binacional, aun derogándose el mismo; el contrato individual que cada uno de los braceros contrajo con su empleador aún contaban con valor legal, por lo que tenían la obligación de continuar laborando hasta finalizar la temporada de cosecha. ${ }^{35}$

En un informe redactado el 25 de octubre al secretario de Relaciones Exteriores, diversos consulados mexicanos ubicados en el suroeste de Estados Unidos dieron a conocer si presentaban algún comportamiento anómalo en la cantidad de trabajadores mexicanos indocumentados en los campos agrícolas correspondientes a su jurisdicción, los cónsules de Alpine y Amarillo en Texas, Albuquerque en Nuevo Mexico, Denver en Colorado y Phoenix en Arizona comunicaron que sí habían percibido un incremento en el número de trabajadores mexicanos indocumentados; mientras que Tucson, Naco y Nogales en Arizona, no reportaron ningún comportamiento atípico.

Según datos reportados a la embajada mexicana por parte de la oficina de empleos del estado de Texas, la distribución de trabajadores indocumentados que ingresaron durante los 4 días que permaneció abierta la frontera en la zona de El Paso fue la siguiente:

34 Carta de Rafael de la Colina al Secretario de Estado estadounidense Robert A. Lovett, 18 de octubre de 1948, en ídem.

35 Memorándum de la Secretaría de Estado estadounidense a la embajada mexicana en Washington, 27 de octubre de 1948. 


\begin{tabular}{c|c}
\hline Región & Número \\
\hline Pecos y Valle de Texas & 3141 \\
\hline Nuevo México & 3078 \\
\hline $\begin{array}{c}\text { Great Western Sugar Co., } \\
\text { de Denver, Colorado }\end{array}$ & 489 \\
\hline $\begin{array}{c}\text { Holly Sugar Co., de Colorado } \\
\text { Springs }\end{array}$ & 110 \\
\hline Arizona & 25 \\
\hline Total & $\mathbf{6 8 4 3}$ \\
\hline
\end{tabular}

La enérgica oposición hacia esta política aplicada unilateralmente por el gobierno de los Estados Unidos, no solo provino de la autoridad mexicana. Centrales sindicales como la AFL y la CIO, e incluso LULAC se manifestaron en contra de las medidas tomadas por el gobierno estadounidense, ya que de acuerdo a ellos iban en detrimento del salario y calidad de vida de sus agremiados, en especial de los trabajadores estadounidenses de origen mexicano.

El presidente nacional de LULAC, Raúl A. Cortéz, el 18 de octubre envió un telegrama al presidente Truman, con copia a Tom C. Clark, procurador general de los Estados Unidos y al senador Dennis Chávez, donde manifestaba una enfática protesta por parte de la asociación que presidía, en contra de la medida tomada por el INS y la patrulla fronteriza al permitir la entrada de trabajadores indocumentados, los cuales fueron enviados a ranchos de Texas, Nuevo México, Arizona y otros estados del suroeste, demandando la inmediata deportación de dichos trabajadores.

Ocho días después, el 26 de octubre, Watson B. Miller comisionado nacional del INS, remitió una carta a Raúl A. Cortéz donde le "informó" que el citado incidente se trataba de una disposición excepcional de emergencia de carácter temporal y que se dispondrían a regresarlos a México cuando terminara la temporada de cosecha. Según Miller, se determinó utilizar esta medida tras una serie de negociaciones con el gobierno mexicano, el cual, aseguró 
el comisionado "no cumplió su compromiso de establecer un centro de contratación en Ciudad Juárez”. Además comentó que la resolución tomada benefició a los granjeros, quienes no perderán sus cosechas y los "hambrientos trabajadores mexicanos que se encontraban abandonados a su suerte en Ciudad Juárez”.

El 4 de noviembre, Cortéz expide una circular dirigida a Tom C. Clark, y con copia a varios funcionarios públicos del gobierno estadounidense (incluyendo a Watson B. Miller), donde responde a "algunas inconsistencias" que Miller "reporta como hechos" en la carta del 26 de octubre. En primer lugar, Cortéz considera que es falso que la entrada de trabajadores mexicanos "ilegales" no afecte los salarios y calidad de vida de los ciudadanos estadounidenses de origen "latino-americano", además aseguró que hasta donde tenía entendido "el gobierno mexicano no se comprometió a establecer centro de contratación alguno en Ciudad Juárez”; calificando de "hipócrita y oportunista" la política de deportación de la INS en la frontera sur, la cual según Cortéz, se trataba más bien de "una oficina de administración de mano de obra agrícola, encargada de repatriar a los trabajadores solo cuando ya no les fueran necesarios a los grandes productores agrícolas". ${ }^{36}$

La Texas Cotton Ginners Association, en un boletín especial publicado por J. C. Stilley el 26 de octubre, refiriéndose al incidente sucedido en El Paso, argumentó que dicho evento probaba de una vez por todas que "los braceros cruzaron el río para asegurar un pago en dólares estadounidenses y una mejor vida que en su propio país". Además, afirmó que de los 8500 aproximados trabajadores que cruzaron el río los días 14 al 18 de octubre en El Paso, se encontraban recolectando algodón en los estados de Texas y Nuevo México, a quienes se procuraría que recibieran un trato digno, "siendo esta una oportunidad para probar al gobierno mexicano que en Texas y en especial los algodoneros, no deberían volver a ser colocados en lista negra alguna”. ${ }^{37}$

36 Circular de R. A. Cortéz a T. C. Clark, 4 de noviembre de 1948, en George I. Sánchez Papers, LILLAS-Benson Special Collections, caja 62, Exp. 5.

37 Boletín especial de la Texas Cotton Ginners Association, elaborado por J. C. Stilley, 26 de octubre de 1948 en Archivo de la embajada de México en los Estados Unidos, AHSRE, legajo 1453, Exp. 1. 
Como una medida para mejorar las relaciones con México, autoridades del sistema de migración estadounidense, entre los días 8 y 14 de noviembre, entregaron en las oficinas de migración mexicanas ubicadas en Ciudad Juárez a 1509 migrantes mexicanos que presuntamente habían ingresado de manera indocumentada el mes de octubre; del total, 1059 eran hombres adultos, 56 mujeres y 387 menores de edad (353 del sexo masculino y 44, femenino). ${ }^{38}$ Esta cantidad de nueva cuenta fue considerada como insuficiente por oficiales migratorios mexicanos, los cuales se mantuvieron en la postura de suspensión del convenio.

Dicho incidente tuvo una amplia cobertura de la prensa, en especial en los diarios de circulación local. Los días subsecuentes al incidente de El Paso, notas relacionadas aparecieron en la primera plana en prácticamente todos los periódicos texanos, tanto de habla inglesa como hispana; en la prensa angloparlante, entre los días 15 y 19 de octubre se pudieron leer a 8 columnas encabezados como: "Border open to mexican laborers", "Border-Jumping Braceros face trouble at home", "Demand for mexican workers slackens off", entre otras; estas notas fueron escritas principalmente por reporteros locales de El Paso, para los diarios El Paso Times y El Paso Herald-Post, aunque muchas de ellas fueron replicadas por otros medios locales y nacionales.

La mayoría de las notas escritas en idioma inglés hacían énfasis a una "invasión de mojados", en la que en tonos escandalosos y alarmistas hacían referencias de corte racial, sobre las condiciones "casi inhumanas" en las que vivían estos trabajadores, así como los "peligros" que representaban a la sociedad estadounidense la llegada de estos, las cuales además, iban acompañadas de una serie de fotografías de trabajadores mexicanos cruzando a nado el río Bravo, siendo escoltados por la patrulla fronteriza y sobre los

\footnotetext{
38 Relación de personas mexicanas que se encontraban ilegalmente trabajando sin contrato en los campos agrícolas de los Estados Unidos y fueron regresadas a territorio nacional, elaborado por el coronel Raúl Michel, 15 de noviembre de 1948, en Archivo de la embajada de México en los Estados Unidos, AHSRE, legajo 1452, Exp. 7.

39 El Paso Herald-Post, 15 de octubre de 1948.

40 El Paso Times, 15 de octubre de 1948.

41 El Paso Times, 18 de octubre de 1948.
} 
camiones en que fueron transportados.

En cambio, los diarios de habla hispana, en especial La Prensa de San Antonio, puso un mayor énfasis en las tensas relaciones entre los gobiernos mexicano y estadounidense y la posterior ruptura del PB por parte de México. En la nota principal de La Prensa, el 19 de octubre, titulada "México repudia el contrato de braceros", ${ }^{42}$ se destacó que la causa de ello fue la violación al convenio por parte de las autoridades migratorias estadounidenses.

El reportero Art Leibson laboraba para El Paso Times durante el momento del incidente, y llevaba varios años cubriendo notas sobre asuntos migratorios en la frontera sur de Texas. En su artículo "The Wetback Invation", publicado a mediados de 1949, narra su experiencia al reportar dicho suceso. ${ }^{43}$ Liebson afirma que elementos de la patrulla fronteriza no solo permitieron la entrada de miles de jornaleros mexicanos al estado de Texas, también se encargaron de colocarlos en camiones que se encontraban localizados "a unas cuantos cientos de yardas del río" y en los cuales fueron transportados a diversas granjas en los estados de Texas y Nuevo México. El reportero afirma que los camiones se encontraban cargados con "docenas de barras de pan, mortadela, y otros comestibles baratos" con los que atraían a los potenciales trabajadores "aprovechándose del hambre que sobrellevaban".

\section{EL ACUERDO DE 1949: NUEVAS CONDICIONES EN LA DEFENSA DEL BRACERO MEXICANO}

A pesar de la prohibición explícita por el gobierno mexicano para no realizar nuevas contrataciones de braceros desde México, en la primer semana de noviembre de 1948 (unas semanas después del incidente de El Paso), se llegó a un acuerdo entre la SRE y el INS en el que se autorizarían las recontrataciones de brace-

42 La Prensa de San Antonio, 19 de octubre de 1948.

$43 \mathrm{El}$ artículo titulado "The Wetback Invation" escrito por Art Leibson fue incluido en un reporte preliminar sobre "mojados", publicado por George I. Sánchez y Lyle Saunders el 9 de junio de 1949, que fue localizado en George I. Sánchez Papers, LILLAS-Benson Special Collections, caja 72, Exp. 23, y posteriormente publicado en la edición de otoño de la revista Common Ground, pp. 11-19. 
ros laborando en territorio estadounidense hasta por un periodo de seis meses. De acuerdo con la SRE la resolución fue tomada para garantizar que los agricultores estadounidenses no perdieran sus cosechas y para dar tiempo a las autoridades migratorias de ambos países para preparar un paulatino regreso de los braceros a México.

Posteriormente, el 6 de diciembre, se realiza una reunión entre Paul Daniels en calidad de jefe de la oficina de repúblicas americanas del Departamento de Estado de los Estados Unidos, con el encargado de negocios ad interum de México, Rafael de la Colina donde se analizó la posibilidad de una renovación más del convenio. ${ }^{44}$ Tanto Daniels como De la Colina, consideraron que dadas las condiciones vividas por ambos países, la ausencia del PB generaría otra serie de problemas: aumentaría el flujo indocumentado de trabajadores mexicanos, limitaría la capacidad de acción de la embajada y los consulados mexicanos en Estados Unidos para proteger a sus connacionales, además argumentaron que se corría el riesgo de que aumentaran las prácticas inescrupulosas de los granjeros, como disminuir el salario y en general empeorar las condiciones de vida tanto para trabajadores agrícolas mexicanos como estadounidenses.

Tras ocho meses de negociaciones, el 1. ${ }^{\circ}$ de agosto de 1949 se firmó un nuevo convenio laboral. Entre las nuevas condiciones destacaron el establecimiento de un mecanismo para "legalizar" a los trabajadores indocumentados, en condiciones similares al acuerdo de marzo de 1947, quedando consignada la United States Employment Service (USES), como la agencia estadounidense que se encargaría de regular y vigilar a los empleadores. Entre las facultades conferidas al USES se encontraban el determinar en cuáles regiones los braceros mexicanos eran más necesarios, garantizando no desplazar a los trabajadores domésticos, y emprender campañas educativas entre los agricultores estadounidenses sobre los derechos laborales de los braceros.

44 Memorándum de la conversación entre R. De la Colina y P. Daniels, 6 de diciembre de 1948, archivo de la embajada mexicana en Washington, AHSRE, legajo 1453, Exp. 6. 
Además en este acuerdo se incluyeron cláusulas en contra de la discriminación racial, información sobre las condiciones de pago, el reconocimiento de unos estándares de condiciones de vida mínimos aceptables, la prohibición de establecimiento de tarifas diferenciadas, condiciones de transportación seguras, empleo máximo de ocho horas diarias, estableciendo los domingos como día libre de trabajo, revisión y atención médica gratuita por cuenta del patrón, en caso de ser necesaria, entre otras garantías incluidas en versiones previas del acuerdo laboral.

Junto con la aprobación del convenio y el contrato individual de trabajo, también se publicó en ambos idiomas, un manual de "interpretaciones conjuntas" y un instructivo para la contratación de los trabajadores. ${ }^{45}$ En ambos documentos se específica puntualmente los procedimientos burocráticos que tenían que seguir cada una de las instancias interesadas para el cumplimiento del convenio. Según lo estipulado, los individuos o asociaciones que desearan contratar mano de obra agrícola mexicana deberían estar registrados ante el USES, quien decidiría si aprueba la solicitud tomando en cuenta la pertinencia de la misma con respecto a la viabilidad de contratar mano de obra doméstica; si esta fuera aprobada sería turnada al INS, quien determinaría el número de braceros que se necesitan; posteriormente se enviaría una copia por triplicado de la determinación del INS al gobierno mexicano, repitiéndose una al consulado más cercano, otra a un centro de contratación en México y la tercera al archivo de la SRE.

Es de notarse que para este momento, la decisión de a dónde serían enviados los trabajadores dependería únicamente de autoridades estadounidenses, siendo las copias al gobierno mexicano meramente informativas. Los criterios que deberían ser tomados por las autoridades consulares y/o empleados de la SRE para determinar si en alguna localidad o empleador estadounidense cometieran actos discriminatorios contra mexicanos serían los siguientes:

45 Instructivo para la contratación de trabajadores agrícolas mexicanos, $1 .^{\circ}$ de agosto de 1949. 
a) Comprobación de las denuncias con hechos, a fin de no basar una conclusión en premisas falsas o infundadas;

b) Las acusaciones no se deberían basar en simples apreciaciones generales u opiniones personales de los informantes, e

c) Inventariar la totalidad de los hechos comprobados y clasificarlos.

En caso de considerarlo necesario, SRE le informaría a la embajada de Estados Unidos en México las regiones en las que se presentaran actos de discriminación contra mexicanos, posteriormente el embajada le notificaría esto al USES, en caso de concordar con la apreciación del gobierno mexicano, se lo comunicaría al INS con la finalidad de que no expidiera autorizaciones para que en la cita se contrasten trabajadores mexicanos; no obstante, si la apreciación del USES no coincidiera con la del gobierno mexicano a través de sus consulados, la SRE podría exigir una declaración firmada por las autoridades del condado estipulando que no permitirían actos discriminatorios contra mexicanos que presten servicios en su localidad y que en caso de que el consulado mexicano fuera informado sobre la existencia de actos discriminatorios contra mexicanos, las autoridades locales estadounidenses cooperarían plenamente con el personal para asegurar la aclaración de las denuncias; quedando prácticamente en una declaración de "buenas intenciones" por parte de las autoridades locales pero sin ninguna utilidad en la práctica.

Este mecanismo funcionaba como un blindaje para el gobierno estadounidense y los empleadores, haciendo prácticamente imposible que desde una primera instancia se practicaran "las políticas de veto" a zonas determinadas por parte del gobierno mexicano; por lo que significó la anulación de las políticas unilaterales de veto, permitiendo que estados como Texas y algunos condados a los que se les había aplicado estas políticas de prohibición les fueran enviados trabajadores mexicanos de manera documentada amparados bajo este convenio. Es decir, que la llamada "lista negra” de la que tanto se quejaban y hacían referencia los granjeros texanos, había dejado de tener una validez práctica. 
Este hecho significó un severo revés a la política consular de la SRE sobre la protección a los trabajadores agrícolas contratados en el marco del PB, y la aceleración del desgaste de su capacidad de negociación diplomática con los Estados Unidos. A partir de entonces, la capacidad de acción de los consulados para la defensa los braceros se vería paulatinamente mermada tras cada negociación, imponiendo procesos burocráticos cada vez más complejos tendientes a beneficiar al empleador sobre el trabajador.

\section{CONCLUSIONES}

Al inicio de las negociaciones, el contexto económico global enmarcado por la economía de guerra, daba al gobierno mexicano un mayor margen de negociación que supo aprovechar imponiendo una serie de condiciones para controlar y limitar el flujo de mano de obra agrícola que se iba con su vecino del norte.

A pesar de que algunos autores argumentan que la medida tomada por las autoridades mexicanas para impedir el flujo de campesinos a Texas y vecinos estados del sur no fue la más eficiente -pues promovió la partida de miles de mexicanos de manera indocumentada-, sirvió como presión para que mejoraran, al menos en papel, las condiciones de vida de los mexicanos residentes en dichas entidades. Aunque, las condiciones de vida de los braceros distaban mucho de ser las idóneas, si no hubiera sido por la presión del gobierno mexicano, tal vez hubieran sido mucho peores.

Algunas de las disposiciones tomadas por Texas para "garantizar" un mejor trato a los mexicanos (como la Texas Good Neighbord Comission o la Caucasian Race Resolution) durante los primeros años del programa, así como las constantes peticiones por parte de los estados excluidos hacia el gobierno mexicano para que les fueran enviados trabajadores agrícolas; ponen de manifiesto que la postura del gobierno mexicano logró doblegar y sobreponerse, al menos por un tiempo, a los intereses económicos de los productores locales estadounidenses. No obstante, tras el fin de la SGM las condiciones económicas se fueron modificando, 
dejando al Estado mexicano en una posición débil que se tradujo en una posición de mayor vulnerabilidad del bracero frente a su empleador.

El incidente de El Paso es uno de los episodios de quiebre en las relaciones entre estos dos países y marcó el futuro del Programa Bracero. Este suceso logró evidenciar una perdida en la capacidad de negociación de las autoridades mexicanas, de tal manera que sirvió como antesala para eliminar completamente las políticas de veto y marcar el inicio de una nueva etapa en la que paulatinamente el gobierno mexicano cedía a los intereses estadounidenses.

No obstante, no se puede decir que la política diplomática mexicana durante este periodo previo las negociaciones de 1949 fuera un fracaso rotundo; hay que reconocer que al incidir de manera directa a que condados o entidades mandaran a sus braceros tuvo su grado de efectividad por lograr suavizar las relaciones obrero-patronales, estableciendo un mecanismo de presión con la finalidad de contrarrestar las políticas de malos tratos y vejaciones a los ciudadanos mexicanos laborando en el sector agrícola estadounidense. Si estas políticas no se hubieran implementado, hubieran modificado sustancialmente el posterior desarrollo del PB.

Aunque el PB continuó renovándose por unos años más, fue tras los acuerdos de 1949 cuando el gobierno mexicano pierde gran parte de su capacidad de negociación. Si bien, la inclusión de Texas y otros estados del sur en el convenio laboral no significó el fin inmediato de las políticas de "veto", esto fue el inicio de un periodo de declive en la actividad de protección consular. Pese a que en 1950, debido a la Guerra de Corea, la diplomacia mexicana logró robustecer los mecanismos de defensa al trabajador mexicano, y con ello mejorar sus un poco condiciones laborales; a partir de 1953, tras la culminación del conflicto bélico en Asia, la SRE vuelve a perder su capacidad de negociación, paulatinamente los intereses de los productores agroindustriales terminan por imponerse haciendo más innecesaria la existencia de un programa binacional de importación de mano de obra. 
Al inicio de la década de los sesenta, el PB había dejado de ser política y económicamente redituable para Estados Unidos. El incremento en la mecanización del sector agroindustrial había suscitado un detrimento en la demanda de mano de obra que fácilmente podía ser absorbida por parte de la comunidad mexicoamericana o inmigrantes indocumentados; además, el surgimiento del movimiento en pro de los derechos civiles había gestado una opinión poco favorable del convenio laboral con México entre un grupo mayoritario de ciudadanos estadounidenses. Esto, aunado a la debilidad política del gobierno mexicano frente a los intereses económicos estadounidenses, propició que el congreso de los Estados Unidos decidiera de manera unilateral el dar por terminado el convenio laboral binacional en diciembre de 1964.

\section{BIBLIOGRAFÍA}

Alanís Enciso, Fernando Saúl (1999), El primer programa bracero 1917-1918. El Colegio de San Luis, San Luis Potosí, 119 pp.

----- (2007), Que se queden allá, El gobierno de México y la repatriación de mexicanos en Estados Unidos (1934-1940). El Colegio de la Frontera Norte, El Colegio de San Luis, 346 pp. Blanton, Carlos Kevin (2015), George I. Sánchez: The Long Fight for Mexican American Integration, Yale University Press, 383 $\mathrm{pp}$.

Bustamante, Jorge A. (1976), Espaldas mojadas, cuaderno del Centro de Estudios Sociológicos 9, El Colegio de México, 46 pp.

Chacón, Susana (2008), La relación entre México y Estados Unidos (1940 -1955) entre el conflicto y la cooperación, FCE/ITESM, $232 \mathrm{pp}$.

Calavita, Kitty (1992), Inside the State: The bracero program immigration and the I.M.S., Routgler, Nueva York, 243 pp.

Cohen, Deborah, (2011), Braceros: Migrants Citizens and Transnational Subjects in the Postwar United States and Mexico, The University of North Carolina Press, 328 pp.

Coalson, George Otis, 1977, The Development of the Migratory Farm Labor System in Texas, 1900-1954, San Francisco, R\&E Research Associates, $132 \mathrm{pp}$. 
Craig, Richard B. (1971), The Bracero Program, Interest Groups and Foreign Policy, University of Texas Press, 233 pp.

Driscoll, Barbara (1998), Tracks North: The Railroad Bracero Program of World War II, University of Texas at Austin, $236 \mathrm{pp}$.

Durand, Jorge (2006), Programas de trabajadores temporales: Evaluación y análisis del caso mexicano, Consejo Nacional de Población, México D. F., 106 pp.

----- (2007), Braceros, la mirada mexicana y estadounidense. Antología 1945-1964, Senado de la República LX Legislatura/ Universidad Autónoma de Zacatecas/Miguel Ángel Porrua, 527 $\mathrm{pp}$.

Galarza, Ernesto (1964), Merchants of Labor, The Mexican Bracero Story, an Account of the Manage Migration of Mexican Farm Workers in California, 1942-1960, McNally \& Loftin Publishers, $294 \mathrm{pp}$.

Gamboa, Erasmo (1990), Mexican Labor and World War II: Braceros in the Pacific Northwest. University of Texas Press, 178 pp. García, Juan Ramón (1980), Operation Wetback, The Mass Deportation of Mexican Undocumented Workers in 1954, Greenwood Press, 268 pp.

Grijalva, Aidé y Rafael Arriaga Martínez (coords.) (2015), Tras los pasos de los braceros: entre la teoría y la realidad, IIS-UABC y Juan Pablos Editores, 442 pp.

Griswold Del Castillo, Richard and Richard Steele (2008), World War II and the Mexican Civil Rights, The University of Texas Press, $245 \mathrm{pp}$.

Gritter, Matthew (2012), Mexican Inclusion: The Origins of Anti-Discrimination Policy in Texas and the Southwest, Texas A\&M University, $160 \mathrm{pp}$.

González, Gilbert (1999), Mexican Consuls and Labor Organizing: Imperial Politics in the American Southwest, $210 \mathrm{pp}$.

González Navarro, Moisés (1993), Los extranjeros en México y los mexicanos en el extranjero, volumen 2, El Colegio de México, $508 \mathrm{pp}$.

González Pérez, Cándido (2010), El programa Bracero-The Bracero Program, Universidad de Guadalajara, 100 pp. 
Lorey E., David (1990), United States-Mexico border statistics since 1900. The Regents of the University of California, $475 \mathrm{pp}$.

Majka, L. C., y Majka, T. J. (1982), Farm Workers Agribussines and the State, Temple University Press, $346 \mathrm{pp}$.

Massey, Douglas, Jorge Durand y Noland J. Malone (2009),They Saved the Crops: Labor, Landscape, and the Struggle Over Industrial Farming in Bracero-Era California, Miguel Ángel Porrúa/Universidad Autónoma de Zacatecas, 208 pp.

Mitchell, Don (2012), They Saved the Crops: Labor, Landscape, and the Struggle Over Industrial Farming in Bracero-Era California, University of Georgia Press, $576 \mathrm{pp}$.

Overmyer-Velázquez, Mark (2011), Beyond la Frontera: The History of Mexico-U.S. Migration, Oxford University Press, 350 pp.

Torres Ramírez, Blanca (1979), México en la Segunda Guerra Mundial, El Colegio de México, 380 pp.

Torres Ramírez, Blanca (1979b), Hacia la utopía industrial, El Colegio de México, $331 \mathrm{pp}$.

Rivas-Rodríguez, Maggie y Emilio Zamora (2009), Beyond the Latino World War II Hero. The Social and Political Legacy of a Generation, University of Texas Press, $247 \mathrm{pp}$.

Vázquez, Josefina y Lorenzo Meyer (2003), México frente a Estados Unidos. Un ensayo histórico 1776-2000, Fondo de Cultura Económica, 262 pp.

Velazquez Flores, Rafael (2007), La política exterior de México durante la Segunda Guerra Mundial Editorial Plaza y Valdés, 205 $\mathrm{pp}$.

Zamora, Emilio (2003), The World of the Mexican Worker in Texas, Texas A\&M University Press, 285 pp.

----- (2009). Claiming Rights and Righting Wrongs in Texas: Mexican Workers and Job Politics during World War II, Texas A\&M University, $318 \mathrm{pp}$.

Zorrilla, Luis G. (1965), Historia de las relaciones entre México y los Estados Unidos de América volumen 1, Miguel Ángel Porrúa, 608 pp. 


\section{CAPÍTULOS DE LIBRO}

Alanis Enciso, Fernando Saúl (2011), “The repatriation of Mexicans from the United States and Mexican Nationalism", en Overmyer-Velázquez, Mark, Beyond la Frontera, The History of the Mexico-U.S. migration, Oxford University Press, pp. 51-78. Basurto, Jorge (1984), "Del avilacamachismo al alemanismo", en

La clase obrera en la historia de México, tomo 11, Instituto de Investigaciones Sociales UNAM/Siglo XXI editores.

García y Griego, Manuel (1996), "The importation of Mexican Contract Laborers to the United States", en David Gutiérrez, Between two worlds: Mexican immigrants in the United States, Wilmington, Del., Scholarly Resources, pp. 45-85.

Gamio, Manuel (1975), "Política general y política de población”, en Gamio, Manuel, Antología, Coordinación de humanidades UNAM, Biblioteca del estudiante universitario, pp. 3-27.

Jones, Robert C. (2007), "Los braceros mexicanos en Estados Unidos durante el periodo bélico: el programa mexicano-estadounidense de prestación de mano de obra", en Jorge Durand, Braceros, la mirada mexicana y estadounidense. Antología 1945-1964. Senado de la República LX Legislatura/Universidad Autónoma de Zacatecas/Miguel Ángel de Porrúa, pp. 85-154.

Meyer, Lorenzo (2004), "La institucionalización del nuevo régimen”, en Historia General de México Versión 2000, El Colegio de México, Centro de Estudios Históricos, pp. 825-878.

Paz Salinas, María Emilia (1990), "México y la defensa hemisférica, 1939-1942”, en Rafael Loyola (coord.), Entre la guerra y la estabilidad política: el México de los 40, Grijalbo/Conaculta, pp. 49-82.

Rivero, Martha (1990), "La política durante la economía de guerra”, en Rafael Loyola (coord.), Entre la guerra y la estabilidad política: El México de los 40, Grijalbo/Conaculta, pp. 13-47.

Ruiz, Ramón Eduardo (1994). "Raza y destino nacional”. En María Esther Schumacher, Mitos en las Relaciones México-Estados Unidos, Fondo de Cultura Económica/Secretaría de Relaciones Exteriores, pp. 233-251. 
El veto meXicano hacia TeXas, el incidente de El Paso y su influencia...

\section{ARTÍCULOS EN REVISTAS ARBITRADAS}

Bustamante, Jorge A. (1997, invierno), "Mexico-United States Labor Migration Flows", en International Migration Review, Vol. 31, Núm. 4, pp. 1112-1121.

Carrigan, William D., y Clive Webb (2003, invierno), "The Lynching of Persons of Mexican Origin or Descent in the United States, 1848 to 1928”, en Journal of Social History, Vol. 37, Núm. 2, pp. 411-438.

Chacón, Susana (2009, julio-septiembre). Política migratoria: Proceso negociador 1947-1954, en Foro Internacional, Vol. XLIX, Núm. 3, pp. 518-558.

Cohen, Deborah (2006, primavera), "From Peasant to Worker: Migration, Masculinity, and the Making of Mexican Workers in the US", en International Labor and Working-Class History, Núm. 69, pp. 81-103.

Cornelius, W. A. (2001), "Death at the border: efficacy and unintended consequences of US immigration control policy”, en Population and Development Review, Vol. 27, Núm. 4, pp. 661-685.

Cruz, García, Mauricio (2011, julio-septiembre), "Gobierno y movimientos sociales ante la Segunda Guerra Mundial”, en Foro Internacional, Vol. LI, Núm. 3, pp. 458-504.

Gamboa, Erasmo (1987, agosto), "Braceros in the Pacific Northwest: Laborers on the Domestic Front, 1942-1947", en Pacific Historical Review, Vol. 56, Núm. 3 pp. 378-398.

Gilmore, N. Ray y Gladys W. Gilmore (1963, agosto), "The Bracero", en California Pacific Historical Review, Vol. 32, Núm. 3, pp. 265282.

Grove, Wayne A. (1996, primavera), "The Mexican Farm Labor Program, 1942-1964: Government-Administered Labor Market Insurance for Farmers", en Agricultural History, Vol. 70, Num. 2, Twentieth-Century Farm Policies, pp. 302-320.

Guglielmo, Thomas A. (2006, marzo), "Fighting for Caucasian Rights: Mexican Americans, and the Transnational Struggle for Civil Rights in World War II Texas", en The Journal of American History, Vol. 92, Núm. 4, pp. 1212-1237. 
Hernandez, Kelly L. (2006, invierno), "The Crimes and Consequences of Illegal Immigration: A Cross Border Examination of Operation Wetback, 1943-1954", en Western Historical Quarterly, Vol. 37, Núm. 42, pp. 421-444.

----- (2009, octubre), "Mexican Immigration to the United States", OAH Magazine of History, Vol. 23, Núm. 4, pp. 25-29.

Henderson, Timothy (2011, diciembre), "Bracero blacklists: Mexican migration and the unraveling of the good neighbor policy", The Latin Americanist, pp. 199-217.

Jacobs, Paul (1959, 22 de enero), “The Forgotten People”, en The Reporter Magazine, pp. 13-30.

Jones, Lamar B., Rice G. Randolph (1980), "Agricultural labor in the southwest, the post bracero years", Social Science Quarterly (University of Texas Press), Vol. 61, Núm. 1, pp. 86-94.

Kibbe, Pauline (1949, otoño), "The American Standards for All Americans", en Common Ground, pp. 19-27.

Liebston, Art (1949, otoño), “The Wetback Invasion”, en Common Ground, pp. 11-18.

Martin, Philip (2002, invierno), "Mexican Workers and U. S. Agriculture: The Revolving Door”, International Migration Review, Vol. 36, Núm. 4, pp. 1124-1142.

Martin, Philip L. y John Mamer (1982), “The Farm Labor Market”, Proceedings of the Academy of Political Science, Vol. 34, Núm. 3, pp. 223-234.

Mize, Ronald L. Jr. (2006), "Mexican Contract Workers and the U.S. Capitalistic Agricultural Labor Process: The Formative Era 1942-1964", en Rural Sociology, Vol. 71, pp. 85-108.

Núñez Regueiro, M. Clara, (2008). "La Casa Dividida: Dinámica de la construcción de identidades nacionales en los Estados Unidos" en Revista Andes de la Universidad de Salta Argentina, Núm. 19, pp. 29-63.

Scruggss, Otey M. (1963, agosto), "Texas and The Bracero Program (1942-1947)" en Pacific Historical Review, Vol. 32, Núm. 3, pp. 251-264.

Vezina, Catherine (2016, primavera), "Consideraciones trasnacionales sobre la gestión del Programa Bracero, 1946-1952”, en Relaciones, Núm. 146, pp. 213-249. 
Wayne A., Grove (1983, enero). “The Mexican Farm Labor Program, 1942-1964: Government-Administered Labor Market Insurance for Farmers", Journal of Contemporary History, Vol. 18, Núm. 1, pp. 43-60.

\section{TESIS CONSULTADAS}

COHEN, Deborah (2001), Masculine Sweat, stop-labor modernity: Gender, race and nation in the mid twentieth century, Mexico and the US, tesis doctoral, University of Chicago.

ZAPATA Rivera, Rosa Verónica (2009), Voces y contravoces de la migración: la experiencia migratoria de los mexicanos en los Estados Unidos durante el Programa Bracero, tesis de maestría, UNAM.

ZAZUETA Quintero, Carlos Humberto (1978). La formación de la frontera norte; el caso de Baja California tesis de maestría. El Colegio de México.

\section{FUENTES DOCUMENTALES}

- Archivo Histórico de la Secretaría de Relaciones Exteriores

- Colección Embajada de México en los Estados Unidos

- LILLAS-Benson Special Collections UT Austin

- George I. Sánchez Papers

- The Lorenzo Zavala Texas State Archives

- Beauford H. Jester records, 1946-1949

\section{FUENTES HEMEROGRÁFIAS}

- El Paso Times

- El Paso Herald-Post

- La Prensa de San Antonio 